\title{
A DÚVIDA DE DESCARTES E A SUBSTÂNCIA ARISTOTÉLICA
}

João Paisana

O pensamento de Descartes deu origem a uma profunda inflexão na filosofia ocidental. Podemos afirmar que o cartesianismo constituiu uma pedra fundamental na modernidade filosófica e, sobretudo, está na origem da "guinada subjectiva" da filosofia moderna.

O novo papel atribuído à subjectividade conduziu a uma aparente ruptura com toda a filosofia anterior, em especial com a Escolástica de origem aristotélica. Na verdade a oposição à filosofia escolástica já tinha sido desenvolvida desde o Renascimento, com pensadores como Campanella, Giordano Bruno e Galileu, entre muitos utros. Por outro lado, como mostrou Etienne Gilson em Etudes sur le rôle de la pensée médiévale dans la formation du systèrne cartésien ${ }^{1}$ o pensamento de Descartes revela ainda uma apreciável herança da filosofia medieval, devendo ser compreendido preferentemente mais como diálogo com ela do que como pura e simples -posição.

Segundo pensamos, embora com profundas alterações, a questão central para Descartes mantém-se a questão aristotélica: pretende-se igualmente fundamentar a validade do enunciado predicativo, do logos apofântico. A primazia concedida por Aristóteles ao logos apofântico não só se mantém como é ainda radicalizada. Por este motivo o pensamento cartesiano apresenta agora um mais marcado pendor teoricista do que a filosofia do Estagirita. A ética de Descartes é uma "moral provisória" (Discurso do Método 3 . $^{\text {a }}$ parte), pelo menos tal como foi redigida, e não encontramos nos escritos do filósofo francês um tratado de Retórica ou uma Poética.

Os escritos filosóficos de Descartes, ao contrári de Aristóteles, não procuram inicialmente elaborar uma teoria do real, mas pretendem previa-

\section{J. Vrin, Paris, 1930}

Phainomenon, Lisboa, Edições Colibri, 2001, pp. 87-97

DOI: 10.2478/phainomenon-2001-0005

FCT 
mente determinar a validade do conhecimento, bem como determinar um critério que permita estabelecer essa mesma validade.

Tanto o Discurso do Método como as Meditações Metafísicas ou Os Princípios da Filosofia começam por referir a dificuldade em "estabelecer alguma coisa firme e constante nas ciências". Será esta dificuldade que conduz à dúvida metódica, uma vez que os conhecimentos que nos foram transmitidos não apresentam o grau de certeza necessário para os tornar indubitáveis e "servirem de base firme para uma autêntica ciência".

Numa primeira aproximação parecerá que o carácter dubitável dos conhecimentos encontra a sua origem na falta de fiabilidade dos sentidos: "tudo o que recebi até ao presente por o mais verdadeiro e seguro, aprendi-o dos sentidos ou pelos sentidos: ora algumas vezes experimentei que estes sentidos eram enganadores, e é prudente não se fiar nunca inteiramente naqueles que nos enganaram uma vez."2

A posição de Descartes surgiria assim como oposta à opinião defendida por Aristóteles; com efeito, enquanto o filósofo francês nos diria que os sentidos nos enganam, o Estagirita afirmaria que não há erro possível relativamente aos sensíveis próprios, mas que o erro apenas seria possível quando pretendíamos ultrapassar os dados sensíveis em direcção à substância que os suportaria, através da predicação, do juízo.

Notemos, no entanto, que os exemplos dados por ambos os autores para ilustrar a possibilidade de erro são extremamente semelhantes.

Diz-nos Descartes: "se por casualidade eu não olhasse da janela homens que passam na rua, à vista dos quais não deixo de dizer que vejo homens .... e no entanto que vejo eu desta janela além de chapéus e mantos, que podem cobrir espectros ou simulacros de homens que apenas se movem por fios (ressorts), mas eu julgo que são verdadeiros homens; e assim eu compreendo pela única potência do julgar que reside no meu espírito, o que cria ver com os meus olhos."3

Por sua vez Aristóteles: “a sensação dos sensíveis próprios é sempre verdadeira ou, pelo menos, sujeita o menos possível ao erro. A percepção de que estes sensíveis próprios são acidentes [atributos de uma substância que não possuem existência autónoma] vem em segundo lugar, e aqui já o erro pode surgir; porque, que o sensível seja branco, é um ponto onde não nos podemos enganar, mas que o branco seja tal coisa determinada, ou uma outra, neste ponto o erro é possível." 4

Em ambos os casos o erro não se situaria ao nível dos sentidos, mas apenas quando através do juízo ultrapasso os dados sensíveis em direcção ao

\footnotetext{
${ }^{2}$ Descartes IX Méditations Métaphysiques, 1. ${ }^{a}$ Medit., Ed. Adam et Tannery, J. Vrin, Paris, p. 14 ${ }^{3}$ Ibid., 2. ${ }^{a}$ Medit., p. 25 . O itálico é nosso.

${ }^{4}$ Aristóteles De Anima, III, 3, 428b 18 (trad. Francesa de Tricot) J. Vrin, Paris, 1959
} 
sujeito que os funda, à substância, o erro se torna possível. Em Os Princípios da Filosofia diz-nos ainda Descartes: "quando percebemos qualquer coisa, nós não estamos de maneira alguma em perigo de nos enganar, se nós não julgamos de qualquer modo."5

$\mathrm{Na}$ verdade o que Descartes pretende afirmar não é tanto que os sentidos são a fonte do erro, mas que os dados sensíveis são insuficientes para fundar um enunciado predicativo.

As posições de Descartes e Aristóteles não se revelam de modo algum, neste ponto, inconciliáveis, mas ambos referem igualmente o enunciado predicativo, o logos apofântico, como fonte de possível erro.

A concordância entre os dois autores vai mesmo mais longe, uma vez que ambos aceitam que a substância primeira, o indivíduo, nunca se dá na sua substancialidade, mas apenas através dos seus atributos ou predicados e, como tal, apenas é acessível de um ponto de vista parcial. É precisamente este carácter parcial da estrutura enquanto que apofântica, que já encontramos em Aristóteles, que surge de novo em Descartes. Após ter esclarecido o conceito de substância ${ }^{6}$, diz-nos o filósofo francês: "mas assim que está em questão saber se alguma destas substâncias existe verdadeiramente, isto é, se ela está presentemente no mundo, não é suficiente que ela exista deste modo para fazer que nós a percebamos; porque apenas isso não nos descobre nada que excite qualquer conhecimento particular no nosso pensamento. É necessário, além disso, que ela tenha alguns atributos que possamos notar."7

A substância nunca se dá na sua substancialidade, ela apenas nos é acessível no enunciado predicativo que lhe nota alguns atributos, isto é, apenas nos é acessível parcialmente. É precisamente este carácter parcial do acesso à substância, veiculado pelo enunciado predicativo, que torna o erro sempre possível e, como tal, o nosso conhecimento sempre dubitável. Se não posso duvidar do predicado, que me é dado, posso sempre duvidar da existência do sujeito, da substância. ${ }^{8}$

Mas se o juízo torna o erro possível, Descartes, devido à sua ideia pré-

${ }^{5}$ Descartes IX Les Principes de la Philosophie, ed. Adam et Tannery, j. Vrin, Paris, 1996, p. 39 e ainda Les Méditations Métaphysiques, Ibid..2 p. 29 "agora no que diz respeito às ideias, se as consideramos somente nelas próprias, e se não se relacionam com qualquer outra coisa, elas não podem a propriamente falar ser falsas .... também não é necessário temer que se possa encontrar a falsidade nas afecções ou vontades."

6 "Quando concebemos a substância, concebemos somente uma coisa que exista de tal modo que ela apenas tem necessidade de si própria para existir" Les Principes de la Philosophie, p. 47

${ }^{7}$ Ibid., p. 47

${ }^{8}$ Neste aspecto o pensamento de Husserl aproxima-se, como se sabe, de modo explícito da filosofia cartesiana, por exemplo em Cartesianische Meditationen. No entanto, a posição de Husserl é sensivelmente diferente, uma vez que o filósofo alemão pretende efectuar a sua investigação a nível ante-predicativo. 
via de filosofia, vai afastar como inaceitável todo o conhecimento que não seja indubitável. É o desejo de encontrar como princípio filosófico um conhecimento absolutamente certo que conduziu a que o autor "rejeitasse, como absolutamente falso, tudo em que poderia imaginar a menor dúvida" $\mathrm{e}$ a impedir de "dar crédito às coisas que não são absolutamente certas e indubitáveis, assim como aquelas que parecem manifestamente falsas"; o menor motivo de dúvida seria suficiente para as rejeitar. ${ }^{10}$

A tentativa de encontrar um conhecimento indubitável que pudesse servir de fundamento absoluto a toda a filosofia, prende-se com a própria concepção filosófica de Descartes. Na carta que serve de prefácio à tradução francesa de Os Princípios da Filosofia diz-nos o autor: "a fim de que este conhecimento [filosófico] seja tal, é necessário que seja deduzido das primeiras causas, de modo que, ao estudar para o adquirir, o que se chama propriamente filosofar, é necessário começar pela investigação destas primeiras causas, isto é, dos princípios; e que estes princípios devem ter duas condições: uma, que sejam tão claros e evidentes que o espírito humano não possa duvidar da sua verdade, quando se aplica com atenção a considerá-los; a outra, que seja deles que depende o conhecimento das outras coisas, de modo que eles possam ser conhecidos sem elas, mas não reciprocamente elas sem eles; e que depois disto é necessário tratar de deduzir de tal modo destes princípios o conhecimento das coisas que deles dependem, que não haja nada, em toda a sequência das deduções que se faz, que não seja muito manifesto." 11

A filosofia é assim compreendida segundo o modelo das demonstrações da geometria, de modo que a partir de axiomas (verdades evidentes por si mesmas) se pudessem deduzir teoremas (verdades demonstradas). O que Descartes procura é um conhecimento imediatamente evidente que pudesse servir de axioma fundamental para todo o edifício filosófico, concebido de modo dedutivo. O que caracterizaria a verdadeira filosofia seria a unidade que ela permitiria estabelecer entre todos os conhecimentos científicos. A imagem do conhecimento filosófico, concebido unitariamente sob a metáfora da árvore ${ }^{12}$, ilustra claramente o pensamento do filósofo.

Pensamos que apenas esta concepção do objecto e do método da filosofia conduziu Descartes a afastar todos os conhecimentos, não porque falsos, mas apenas por dubitáveis.

\footnotetext{
${ }^{9}$ Discours de la Méthode, $4 .^{\text {a }}$ parte, p. 35

10 Méditations..., 1. ${ }^{a}$ Medit., p. 14

11 Les Principes ..., p. 2 e ainda pp. 9-10

12 Ibid., p. 14
} 


\section{II}

Descartes pode afastar como falsos conhecimentos meramente dubitáveis porque reivindica um domínio de conhecimentos evidentes, absolutamente certos, relativamente aos quais não seja possível qualquer dúvida.

Se de modo geral Descartes aceita, tal como Aristóteles, que a substância não se dá na sua substancialidade devido ao modo parcial como temos acesso a ela - o que torna a dúvida sempre possível - por contra, agora em clara oposição ao Estagirita, o filósofo francês afirma a existência de uma substância que se dá de modo absoluto, na sua substancialidade, relativamente à qual não tem sentido qualquer dúvida: o ego.

Ao inverso de todas as outras substâncias, o ego não se dá apenas através dos seus predicados ou determinações, ele dá-se mesmo enquanto sujeito de todas as suas determinações ou atributos ${ }^{13}$. Longe que o ego possa ser colocado em dúvida, como todas as substâncias exteriores, a própria dúvida já pressupõe o ego, visto ser eu que duvido. Referindo a actividade enganadora do génio maligno, diz-nos Descartes nas Meditações: "não há qualquer dúvida que eu sou, se ele me engana, e que ele me engane quanto quiser, ele não poderá nunca fazer que eu seja nada, enquanto eu pensar ser qualquer coisa .... é necessário concluir e ter por constante que esta proposição, eu sou,_eu existo, é necessariamente verdadeira"14 e ainda em Os princípios da filosofia "mas nós não poderíamos mesmo supor que não somos, enquanto duvidamos da verdade de todas estas coisas.... nós não poderíamos impedir-nos de crer que esta conclusão: EU PENSO, LOGO EU SOU, não seja verdadeira, e por consequência a primeira e a mais certa que se apresenta àquele que conduz os seus pensamentos por ordem." 15

O ego é uma substância ${ }^{16}$ e uma substância dada de modo imediato pelo cogito. Poderemos dizer que para Descartes o ego é a única substância que se dá na sua substancialidade.

Como se sabe, foi precisamente o carácter imediato de acesso ao ego que desde o tempo do filósofo foi posto em questão. As objecções de Gassendi às Meditações iriam neste sentido: a afirmação eu penso, logo eu sou, não seria fundada de modo imediato, mas seria a conclusão de um silogismo tendo por premissa maior: aquele que pensa é ${ }^{17}$. Assim a afirmação "eu sou, eu existo", não poderia ser considerada como um princípio absoluto auto-fundado, mas pressuporia afirmações anteriores.

13 "Mais je ne connois pas encore assez clairement ce que je suis, moi qui suis certain que je suis" Descartes IX - Méditations..., p. 19

14 Ibid. p. 19

15 Les Principes..., p. 27

16 Méditations, p. 35 e ainda Les Principes, p. 28 "pour connoitre la nature de l'âme et qu'elle est une substance entierement distincte du corps"

17 Méditations (Objections et réponses), Ed. A.T. IX, 1, 206 
O pensamento ou, melhor, o modo de expressão de Descartes apresenta certas inflexões entre o Discurso do Método, as Meditações e Os princípios. Assim enquanto no Discurso ${ }^{18}$ e em Os princípios $^{19}$ a expressão utilizada é "eu penso, logo eu sou" (je pense, donc je suis), por sua vez nas Medita$c_{\text {çoes }}^{20}$ o autor prefere afirmar "eu sou, eu existo" (Je suis. J'existe). No entanto o pensamento do filósofo não deixa lugar a qualquer ambiguidade, pelo menos quanto à sua intenção.

Na resposta às objecções de Gassendi, Descartes afirma que o seu princípio não resulta de um silogismo mas de uma intuição, como as que servem de base às generalizações da Geometria. Em resposta a uma outra objecção, afirma ainda que "eu nego que a coisa que pensa (ego) tenha necessidade de outro objecto além de si próprio para exercer a sua acção." 21

$\mathrm{Na}$ verdade, já ao longo das Meditações o pensamento do filósofo não dá margem para ambiguidades, ao afirmar "eu não conheço ainda bastante claramente o que sou, eu que estou certo que eu sou" 22 e ainda mais claramente, "é muito certo que esta noção e conhecimento de mim mesmo assim precisamente tomados, não depende de modo algum das coisas cuja existência não me é ainda conhecida." ${ }^{23}$ O ego é uma substância que se dá a si mesmo de modo imediato na sua substancialidade e não mediatamente através dos seus atributos ou predicados.

A este propósito será interessante recolher a opinião de outro filósofo, profundo conhecedor e admirador de Descartes, B. Espinoza. Na obra inacabada tendo por título Os princípios da filosofia de Descartes demonstrados segundo o método geométrico, ao discutir igualmente o carácter imediato da afirmação "eu sou", diz-nos o autor: "em relação ao princípio: eu duvido, eu penso, logo eu sou, importa antes de mais observar que esta afirmação não é um silogismo, cuja maior seria passada sob silêncio .... assim este eu penso, logo eu sou, é uma proposição única equivalente a esta: eu sou pensante." ${ }^{24}$ Deste modo, segundo Espinosa, atingimos imediatamente eu sou (pensante) como fundamento de todo o conhecimento.

Relativamente ao ego, como substância, não há dúvida possível, porque não necessito de ir dos predicados para o sujeito, mas, ao inverso, os predicados dão-se através do sujeito.

18 Discours, p. $36 / 7$

19 Principes, p. 27 e p. 29

20 Méditations, p. 19 e p. 21

21 Méditations (Objections et réponses), p. 206

22 Ibid., p. 19

23 Ibid., p 21/22

24 Spinoza Oeuvres I - Les principes de la philosophie de Descartes (trad. Francesa de Ch. Appunh) Garnier-Flammarion, Paris, 1964, pp. 240-1 
O ego será a substância no sentido mais profundo, aquela que não se dá apenas de modo parcial, mas de modo absoluto.

Compreende-se assim que na filosofia moderna o ego tenha sido considerado como o sujeito (subjectus) por excelência, determinando deste modo o âmbito da subjectividade e das filosofias do sujeito.

Com efeito, se o ego é a autêntica substância (subjectus) e se a substância no sentido primeiro é o sujeito de predicados que não é predicável de nenhum sujeito ${ }^{25}$ então o ego é o sujeito em sentido primeiro - o sujeito absoluto de todos os predicados.

Deste modo, todas as afirmações que podem ser proferidas devem referir-se ao ego, como sujeito, seu verdadeiro fundamento. Com Descartes, e após Descartes, o campo da subjectividade alarga-se até incluir em si toda a referência possível.

O ego, o eu sou, surge como o princípio de todos os princípios, um axioma fundante podendo servir de base firme à filosofia tal como Descartes a concebia.

\section{III}

Embora no pensamento de Aristóteles se possa distinguir o nível ontológico e o nível gnoseológico, não se poderá, a propriamente falar, referir uma teoria do conhecimento; por isso preferimos neste caso a expressão de teoria da captação da realidade. Ora, é precisamente com o pensamento cartesiano que o âmbito do conhecimento se vai apresentar como um nível autónomo, tornando possível e exigindo um estudo específico.

Para Aristóteles, recordemos, o conhecido é, antes de mais, fundado na substância (exterior) e só depois é conhecido; o conhecido é, em primeiro lugar, uma determinação (predicado) do real, da substância, que, em segundo lugar, é potencialmente cognoscível. Não há pois lugar para estabelecer uma distinção real entre o conhecido e a determinação da substância, isto é, o conhecimento não possui autonomia ontológica, não possui "suficiência de ser"26.

Não se pode então falar de uma teoria autónoma do conhecimento: com

25 Aristóteles Categorias 2a 11; 34 e Metafísica V, 1017b 24; como vimos, Descartes apresenta uma noção um pouco distinta da substância, pondo o acento no modo como concebemos a sua autonomia e não na predicação; "quando concebemos a substância concebemos somente uma coisa que existe de tal modo que ela apenas tem necessidade de si mesma para existir" Principes..., p. 74 A noção de substância é assim isolada do nível do discurso sobre o ente (logos apofântico) seu verdadeiro solo de origem, tornando-se numa autêntica categoria metafísica, no sentido de supra-sensivel; ela torna-se a tal ponto isolada da experiência que Descartes pode falar de substâncias existentes sem que nós lhe conheçamos qualquer atributo. Principes p. 91

26 Aristóteles afirma que "a ciência em acto é idêntica ao seu objecto" De Anima III, 430 a 20 
efeito, se a ontologia é a ciência do ser enquanto ser, e se conhecer é um modo particular de ser, então o estudo do conhecimento estará subordinado à ciência geral do ser. A Filosofia Primeira é assim Ontologia.

Vejamos que esta situação surge profundamente alterada no pensamento cartesiano. Para Descartes o conhecimento é antes de mais uma determinação do ego, do sujeito cognoscente; poderemos dizer que o conhecimento é fundado em primeiro lugar pelo ego como substância e só depois é possível perguntar pela sua adequação às coisas exteriores. Deste modo, o conhecimento é caracterizado como uma ideia, uma representação, um pensamento um pensamento, isto é, um atributo, o atributo essencial de uma substância que é o ego. Brevemente: o conhecimento surge como predicado de uma substância que é o ego - res cogitans.

Descartes pode assim afirmar que "não há nada que nos excite a conhecer o que quer que seja, que não nos conduza ainda a conhecer mais certamente o nosso pensamento." ${ }^{27} \mathrm{Ou}$ ainda, referindo o célebre exemplo da percepção de um pedaço de cera, o autor pode dizer, de modo aparentemente paradoxal: "porque se eu julgo que a cera é, ou existe, porque eu a vejo, certamente segue-se bem mais evidentemente que eu sou, ou que eu próprio existo, porque eu a vejo. Porque pode acontecer que o que eu vejo não seja com efeito cera; pode também acontecer que eu não tenha mesmo olhos para ver coisa alguma; mas não pode acontecer que quando eu vejo, ou (o que já não distingo) quando eu penso ver, que eu que penso não seja qualquer coisa." 28

Se o conhecimento é caracterizado como pensamento e o pensamento é o atributo essencial de uma substância que é o ego, então o conhecimento conduz-me directamente ao ego, de que é uma determinação, e só indirectamente a uma possível realidade exterior.

Poder-se-á deste modo falar do âmbito do conhecimento como de um domínio autónomo. O conhecimento é então fundado e desenvolve-se exclusivamente no âmbito da subjectividade. Determina-se assim o domínio próprio do que poderá ser estudado como teoria do conhecimento, o domínio da subjectividade.

$\mathrm{Na}$ verdade, a autonomia do conhecimento considerado como simples determinação da subjectividade, poderá eventualmente conduzir a resultados "excessivos", colocando-se então a questão de saber como o conhecimento poderá transcender a simples subjectividade egológica: como o sujeito poderá "sair" de si para alcançar o objecto e o mundo? Com efeito, diz-nos Descartes: "tudo isto me faz conhecer suficientemente que até esta hora não foi de modo algum por um juízo certo e premeditado, mas apenas por uma cega e temerária impulsão, que eu acreditei que havia coisas fora de mim e dife- 
rentes do meu ser"29 e de modo ainda mais expressivo, "deve saber-se que toda a ideia sendo uma obra do espírito, a sua natureza é tal que ela não exige por si qualquer outra realidade formal, além da que recebe e retira do pensamento, ou do espírito, de que ela é apenas um modo, isto é, uma maneira ou modo de pensar." 30

Após se ter afirmado, através da substancialidade do ego, a autonomia do conhecimento, põe-se pois a questão de saber como não ficamos encerrados no solipsismo, isto é, como é que o conhecimento é conhecimento-do-objecto.

$\mathrm{Na}$ verdade, dentro da perspectiva cartesiana, afirmar que o ego é o sujeito do conhecimento é utilizar manifestamente uma expressão ambígua. Com efeito, por um lado, o ego enquanto substância é o sujeito autónomo de todos os conhecimentos, caracterizados como seus atributos, por outro, o ego enquanto cognoscente é o sujeito de todos os conhecimentos-do-objecto. Por um lado, se o conhecimento é apenas considerado como um atributo do ego, ele mantém a autonomia, mas perde a sua dimensão cognitiva (não tem objecto); por outro, se o conhecimento é apenas considerado como conhecimento-do-objecto, mantém a dimensão cognitiva, mas perde a autonomia, ele não é já um simples atributo do sujeito, mas conhecimento-do-objecto, que o funda. ${ }^{31}$

Deste modo, só depois de se ter determinado a autonomia do conhecimento, determinando o âmbito do que virá a ser a teoria do conhecimento, se virá posteriormente a colocar a questão de saber como o conhecimento (a ideia, o pensamento) atinge a realidade exterior, a realidade objectiva, isto é, como o conhecimento é conhecimento-do-objecto; o que irá exigir a determinação de um critério para a sua validade objectiva, delimitando-se assim a necessidade de uma teoria crítica do conhecimento.

Como se sabe, é à veracidade divina aliada à clareza e distinção dos conhecimentos, assim como à coerência na dedução ("o bom uso do poder de julgar que me foi dado por Deus"), que Descartes recorre para estabelecer tal critério. Uma vez que possuo em mim, de modo inato, a ideia de Deus como "um ser omnisciente, todo poderoso e extremamente perfeito ....ele [o

29 Ibid., p. 31

30 Ibid., p. 32

${ }^{31}$ É esta ambiguidade que vai ferir de equívoco o conceito de conhecimento ao longo da Modernidade e que reapareceu no início do século XX com a célebre polémica entre Husserl e o psicologismo. Segundo pensamos é ainda esta ambiguidade que está na origem da confusão apontada por Rorty a Locke entre explicação e justificação. Rorty cita W. Sellars: "ao caracterizarmos um episódio ou um estado como sendo de conhecimento, não estamos a fornecer uma descrição empírica desse episódio ou estado; estamos a colocá-lo no espaço lógico das razões, da justificação e da capacidade para justificarmos aquilo que dizemos." Rorty, A filosofia e o espelho da natureza (trad. Port. J. Pires), Dom Quixote, Lisboa, 1988, p. 116 
pensamento] julga facilmente pelo que apercebe nesta ideia, que Deus, que é este Ser totalmente perfeito, é ou existe." $32 \mathrm{E}$ o primeiro dos seus atributos que deve ser considerado, "consiste em que ele é muito veraz e a fonte de toda a luz, de modo que não é possível que nos engane." ${ }^{33}$ Segue-se assim que "a faculdade de conhecer que ele [Deus] nos deu, que chamamos luz natural, não percebe nunca qualquer objecto que não seja verdadeiro no que ela apercebe, isto é, no que ela conhece clara e distintamente." 34

Do mesmo modo, nas Meditações é já a veracidade divina que me permite afirmar a verdade dos conhecimentos, claros e distintos, relativos às coisas exteriores, não ficando assim encerrado no ego. "E já me parece que descubro um caminho que me conduzirá desta contemplação do verdadeiro Deus (no qual todos os tesouros da ciência e da sabedoria estão fechados) ao conhecimento das outras coisas do Universo. Porque, primeiro, reconheço que é impossível que jamais me engane, uma vez que em toda a fraude e engano se encontra alguma espécie de imperfeição." 35

Não iremos discutir a prova da existência de Deus apresentada por Descartes, nem a pertinência do critério avançado para fundamentar a validade objectiva do conhecimento relativo às "coisas exteriores" ao eu sou. Desejámos apenas sublinhar o duplo sentido que adquire o termo "conhecimento" no pensamento de Descartes e, através dele, em toda a filosofia moderna.

Dissemos anteriormente que na filosofia de Aristóteles e na Escolástica não se poderia, com propriedade, referir uma teoria do conhecimento como disciplina autónoma. Na medida em que conhecer seria um modo particular de ser, o estudo do conhecer deveria estar subordinado e integrar-se na ciência que estudaria o ser enquanto ser; a Filosofia Primeira (metafísica) seria assim ontologia. Com Descartes e com a filosofia moderna esta situação altera-se.

Com efeito, raciocinando com a Modernidade, se a ontologia é a ciência que estuda o ser enquanto ser, ou o ente enquanto ente, enquanto ciência ela é constituída por um conjunto sistematizado e hierarquizado de conhecimentos. Deste modo, se o conhecimento determina agora o âmbito de um estudo autónomo, então a ciência que estuda o ser, como qualquer outra ciência particular, deverá ser precedida por uma disciplina crítica que estuda o alcance e os limites do conhecimento em geral, antes de abordar o seu objecto particular. A disciplina que estuda o alcance e os princípios do conhecimento - mais tarde teoria do conhecimento - deverá então ser considerada como a Filosofia Primeira.

32 Principes, p. 31
33 Ibid., p. 37
34 Ibid., p. 38
35 Méditations, p. 42/3 
Assim, Os princípios da filosofia de Descartes antes de abordarem o estudo Dos princípios das coisas materiais (2. ${ }^{a}$ Parte), do Mundo visível (3. ${ }^{a}$ Parte) e Da Terra (4. ${ }^{a}$ Parte) começam por abordar Os Princípios do Conhecimento Humano (1. ${ }^{a}$ Parte).

Descartes, se conserva ainda o velho termo de "Metafísica" para denominar a Filosofia Primeira, abandona no entanto a sua caracterização tradicional, para afirmar: "dividi o livro em quatro partes, de que a primeira contém os princípios do conhecimento, que é o que se pode chamar a primeira filosofia ou a metafísica." 36

Naturalmente que uma tal alteração terá profundas consequências. Em primeiro lugar, e não será a menor, no modo de considerar e, como tal, permitir encontrar o ente. Descartes - e com ele a filosofia moderna - propõe um novo modo de encontrar o ente - a experiência cognitiva; ${ }^{37}$ o ente já não será encontrado primariamente nem como substância, isto é, sujeito autónomo de predicados, nem como ens creatum, mas como objecto de conhecimento, isto é, sujeito de predicados no espaço da subjectividade. A experiência é concebida assim exclusivamente a partir da dimensão cognitiva: abre-se o cenário para o empirismo e o racionalismo, figuras maiores da modernidade.

Vemos deste modo que o domínio do conhecimento e da subjectividade como espaço autónomo de investigação, que tão largo papel irá desempenhar na filosofia moderna, é subsidiário da concepção aristotélica de substância.

36 Principes, p. 16 e também p. 14

37 É por isso que a dúvida adquire um lugar preponderante no pensamento cartesiano, ao contrário do pensamento aristotélico onde a própria experiência era compreendida a partir de uma ontologia prévia. 